\title{
Revisiting precision mobile drip irrigation under limited water
}

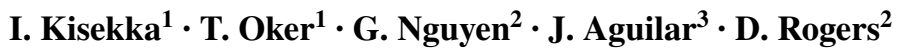

Received: 31 October 2016 / Accepted: 26 August 2017 / Published online: 4 September 2017

(C) The Author(s) 2017. This article is an open access publication

\begin{abstract}
Precision mobile drip irrigation (MDI) describes the application of water through surface drip irrigation lines that are dragged by center pivot or linear move. MDI has the potential to greatly reduce water losses due to wind drift, soil water evaporation, and canopy evaporation. Two studies were conducted with the following objectives: (1) compare soil water evaporation under MDI and LESA; (2) assess soil water redistribution under MDI; (3) compare end-of-season profile soil water under MDI and LESA at two irrigation capacities 3.1 and $6.2 \mathrm{~mm} /$ day and to investigate design objectives that were implemented to overcome problems of earlier MDI designs. The experiments were conducted in western Kansas. Soil water evaporation was 35\% lower under MDI. There was adequate redistribution of soil water in the subsurface. End-of-season soil water was significantly higher $(p=0.001)$ under MDI compared to LESA at the $3.1 \mathrm{~mm} /$ day irrigation capacity. Statistical uniformity of MDI was good ranging between 85 and $90 \%$. The MDI system prevented deep wheel tracks and its redesign eliminated emitter clogging and reduced the frequency of the drip lines moving into the crop. The ability to better manage MDI due to design changes and its demonstration of superior performance in reducing soil water evaporation under limited canopy cover suggests that the system has
\end{abstract}

Communicated by S. Shaughnessy.

I. Kisekka

ikisekka@ucdavis.edu

University of California Davis, Davis 95616, CA, USA

2 Biological \& Agricultural Engineering Department, Kansas State University, Manhattan, USA

3 Southwest Research-Extension Center, Kansas State University, Garden City, USA the potential to enhance crop water productivity in a waterlimited environment.

\section{Introduction}

Projected increases in global population and demand for food, feed, and fiber will cause agricultural water use to increase by approximately $19 \%$ by the year 2050 (UNESCO 2013). In many irrigated areas of the world, water supplies for irrigation are either hydrologically or institutionally constrained. For example, the United States Central High Plains will face challenges maintaining high agricultural productivity under declining ground water supplies from the Ogallala aquifer. The Ogallala aquifer has experienced steep declines in water levels in western Kansas, eastern Colorado, and the Panhandles of Texas and Oklahoma but still remains the major source of irrigation water in this region (McGuire 2012). To cope with limited water supplies, producers need innovative irrigation technologies that can help them increase water productivity. Precision mobile drip irrigation or simply MDI, which integrates drip lines onto a mechanical irrigation system such as a center pivot or lateral move system (Fig. 2), may allow producers to harness the efficiency of drip irrigation technology at a relatively low cost compared to other micro-irrigation technologies, especially in low value row crop production. By applying water on the soil surface between crop rows, it is hypothesized that MDI could eliminate water losses due to spray droplet evaporation, water evaporation from wetted canopy, and wind drift. MDI may also reduce soil water evaporation due to limited wetted surface, especially before canopy closure compared to sprinkler systems. MDI may also reduce runoff potential and wheel track rutting problems. 
The idea of replacing center pivot or lateral move sprinkler nozzles with drip lines is not new. Several researchers have experimented with this concept in the past (Rawlins et al. 1974; Howell and Phene 1983; Helweg 1989; Amir and Dag 1993; Derbala 2003; and Olson and Rogers 2007). Early work on MDI can be traced back to Rawlins et al. (1974) who designed and built a traveling trickle system near Fresno CA that integrated the advantages of drip irrigation with those of a linear move system specifically allowing the ability to irrigate large areas without the need for an extensive pipe network. Howell and Phene (1983) compared traveling trickle drag lines to other irrigation application methods on a linear move system and reported that cotton lint yield of the various irrigation application methods was not significantly different. They noted that trickle drag lines caused many problems including the large power requirements to pull the lines and coiling of the trickle lines on the main pipe line.

Helweg (1989) developed a traveling trickle system for grain and legumes crops to address major limitations of center pivots at the time which included: (1) high pressure requirements, (2) evaporation losses under windy arid environments, (3) wetted canopy that created favorable conditions for some pests and diseases and (4) sometimes application rates exceeding instantaneous infiltration rates. Another problem associated with center pivots is unirrigated corners in areas where land is a limited resource. Although some of the problems have been addressed, e.g., reduction in pressure requirements by replacing impact sprinklers with spray nozzles, and reducing evaporation losses using in-canopy drops; other problems have been created; e.g., increased potential for runoff, especially near the circumference of the circle where application rates may exceed instantaneous infiltration rates. Canopy wetting continues to be a challenge since even with in-canopy drops, the application devices are not parallel to the crop rows and get trapped in the canopy. Helweg (1989) reported that the traveling trickle used $40 \%$ less water compared to a center pivot with sprinkler nozzles to produce the same wheat yields in Saudi Arabia. He also reported no significant differences in yield between wheat planted in circles and wheat planted in straight rows. While straight rows might work for short crops such as wheat or alfalfa, our observation during the 2015 growing season with corn indicates that concentric planting was better at preventing the drip lines from becoming suspended in the canopy.

Amir and Dag (1993) evaluated wetting contours of moving emitters; they reported that high instantaneous application rates of traveling emitters increased uniformity and width of application but increased surface ponding and potential for runoff. These findings have implications on the design and selection of MDI laterals. Derbala (2003) evaluated MDI in Brandenbur, Germany and reported MDI water savings of 10-20\% under potato production compared to center pivot sprinkler irrigation. However, Derbala (2003) did not observe significant differences in sugar beet yield between MDI and center pivot sprinkler irrigation, but reported energy savings of 40 to $50 \%$ for MDI. Olson and Rogers (2007) compared MDI to LESA nozzles on a standard size center pivot (402 m) in Northwest Kansas and reported that there were no significant differences in corn yields between the two application methods. They noted that although water was filtered, MDI experienced clogging but the reduced irrigation application resulting in the same yield as spray nozzles implied MDI had higher crop water use efficiency. All the above studies indicate the potential of MDI to improve water productivity by reducing unproductive water losses. However, the technology has not been widely adopted due to drip line clogging, tangling of drip lines in the canopy, reversing problems and complications associated with circular plantings.

Increased pressure on fresh water resources for irrigation coupled with recent advancements in drip line emitter technology, e.g., pressure compensated (PC) emitters, structural improvements in the way the drip line is connected to the center pivot, as well as improvements in GPS technology to ease circular planting make revisiting the MDI technology attractive. PC emitters ensure a constant flow over a range of pressures which improves uniformity of water application and fertilizers in case of fertigation even under undulating topography. Another advantage of MDI is that in regions where this technology could prove very useful, such as the Southern and Central High Plains, many producers already own center pivots; therefore, the transition from sprinklers to MDI would be relatively easy. MDI could also be useful in other parts of the world where water for irrigation is limited and mechanical systems such as linear move or center pivot systems are used.

Mechanized pressurized irrigation technology has evolved greatly since the invention of the first center pivot by Frank Zyback in the 1950s. In arid and semi-arid areas where evaporative losses are high, center pivots have evolved from using high pressure impact sprinklers to low pressure in-canopy sprinklers. Examples of efficient irrigation technologies being used in the United States south and Central High Plains include Low Elevation Spray Application (LESA), Mid Elevation Spray Application (MESA), and Low Energy Precision Application (LEPA). In addition, a limited number of farmers have installed Subsurface Drip Irrigation (SDI) systems. All these technologies have been shown to have high application efficiencies in various studies (Howell et al. 1991; Schneider and Howell 1993; Lamm et al. 2012). However, adoption of some of these technologies has been limited due to differences in cultural practices as well as cost. LEPA overcomes evaporation losses associated with overhead impact sprinklers such as droplet evaporation, wind drift and canopy evaporation, but LEPA 
requires nearly level ground and specialized tillage such as the dammer diker to enhance surface storage. While LEPA has been adopted in the Southern High Plains, it is not widely used in the Central High Plains. Likewise, SDI adoption is higher in the Southern High Plains than in Central High Plains, but it has also been limited by high initial costs and problems such as poor germination and rodent damage. LESA is used by many producers in the High Plains, but can be associated with low uniformity due to surface redistribution resulting from instantaneous application rates exceeding soil infiltration rates. MESA is used in areas where there are large slopes within fields, although MESA can produce high application uniformity, it has high potential for water evaporation from wetted canopy and wind drift. MDI would overcome some of the problems associated with SDI without the cost of extensive pipe network which can be prohibitive for low value crops. The target audience for this technology will be producers who already own center pivots that have limited irrigation capacity associated with loss of well yield or institutional constrains on water supplies.

To quantify the benefits of new MDI technology, studies were conducted with the following objectives: (1) compare soil water evaporation under MDI and LESA; (2) assess soil water redistribution under MDI; (3) compare end-of-season profile soil water under MDI and LESA at two irrigation capacities 3.1 and $6.2 \mathrm{~mm} /$ day and to investigate design objectives that were implemented to overcome problems of earlier MDI designs including emitter clogging, non-uniform water application and precise positioning of the drip line to minimize interaction with crop canopy.

\section{Materials and methods}

\section{Experimental site}

The study was conducted at the Kansas State University Southwest Research-Extension Center $\left(38^{\circ} 01^{\prime} 20.87^{\prime \prime} \mathrm{N}\right.$, $100^{\circ} 49^{\prime} 26.95^{\prime \prime} \mathrm{W}$, elevation of $887 \mathrm{~m}$ above mean sea level) near Garden City, Kansas. The climate of the study site is semi-arid with mean annual precipitation of $440 \mathrm{~mm}$ and mean annual evapotranspiration of $1943 \mathrm{~mm}$ (1986-2014). The soil at the study site is a deep well-drained Ulysses silt loam (fine-silty, mixed, mesic Aridic Haplustoll) with average $\mathrm{pH}$ of 8.1. Two independent studies were conducted to compare MDI and LESA. Study 1 compared the two application technologies at high well capacity $[98.5 \mathrm{lps} / \mathrm{ha}(4.8$ gpm/acre)] and Study 2 compared the technologies at low well capacity [49.3 lps/ha (2.4 gpm/acre)]. Mimicking a typical center pivot on a 52.6 ha field in western Kansas, this would translate into irrigation capacities of 6.2 and $3.1 \mathrm{~mm} /$ day for Study 1 and Study 2, respectively. The experimental design in each study was a randomized complete block with four replications (each span $42 \mathrm{~m}$ long was a replication having MDI and LESA) as shown in Fig. 1.

\section{Agronomic management}

The experiment was conducted in a field that was previously under fallow. The corn hybrid planted in 2015 was DKC 61-89 GENVT2P (Monsanto Company, St. Louis, MO), with a relative maturity of 111 days. Planting was done on May 18, 2015 at a seeding rate of 79,040 seeds per hectare at a row spacing of $76 \mathrm{~cm}$ using a no-till planter; planting depth was $51 \mathrm{~mm}$. Due to the absence of a GPS system circular planting was accomplished using a marker guided by the center pivot wheel tracks. Nitrogen fertilizer was applied preplant at a rate of $336 \mathrm{~kg} / \mathrm{ha}$ of $\mathrm{N}$ as urea $46-0$ 0 . Weed control involved application of $7.02 \mathrm{l} / \mathrm{ha}$ of Lumax EZ (S-metolachlor, Atrazine, Mesotrione) and $23.9 \mathrm{ml} / \mathrm{ha}$ of Sharpen (Saflufenacial) as pre-emergence herbicide and $383.1 \mathrm{ml} / \mathrm{ha}$ of Mad Dog Plus (Glyphosate) and Prowl H2O (Pendimethalin) as post-emergence herbicides.

\section{Biophysical measurements}

Leaf area index (LAI) was measured periodically using the non-destructive AccuPAR LP-80 Ceptometer (Decagon Inc., Pullman, WA). Final grain yield and above ground dry matter (DM) were done by hand harvesting two $12.2 \mathrm{~m}$ corn rows in the center of each plot at physiological maturity. For DM, grain and stover were separated chopped using a $5 \mathrm{Hp}$ chipper and oven dried at $60{ }^{\circ} \mathrm{C}$ in order to obtain above ground biomass at dry matter basis. Grain yield was harvested on October 06, 2015 and yields were adjusted to $15.5 \%$ nominal moisture content. Harvest index was computed as the ratio of grain yield to aboveground dry matter at maturity. Seed mass was determined by the mean of 500 kernels. Seed number and seeds per ear were computed from plant and ear densities. Critical growth stages were recorded following the University of Illinois corn growth stage guide.

\section{Irrigation management}

Irrigation was applied using a center pivot sprinkler system (Model: Valley 8000 Polyline, 4 Tower 560 feet, Valmont Industries, Inc., Valley, Nebraska) retrofitted with drip irrigation (Fig. 1). To prevent emitter clogging, a $130 \mu \mathrm{m}$ disc filter with a flow rating of $45.4 \mathrm{~m}^{3} / \mathrm{h}$ was installed at the pump station equipped with a Variable Frequency Drive (VFD). Irrigation treatments for the two studies are listed below:

Study 1: $6.2 \mathrm{~mm} /$ day irrigation capacity.

1. MDI-Apply $25 \mathrm{~mm}$ every 4 days.

2. LESA-apply $25 \mathrm{~mm}$ every 4 days. 
Fig. 1 Experimental layout of two experiments comparing mobile drip irrigation to LESA at two irrigation capacities at the Kansas State University Southwest Research and Extension Center near Garden City Kansas

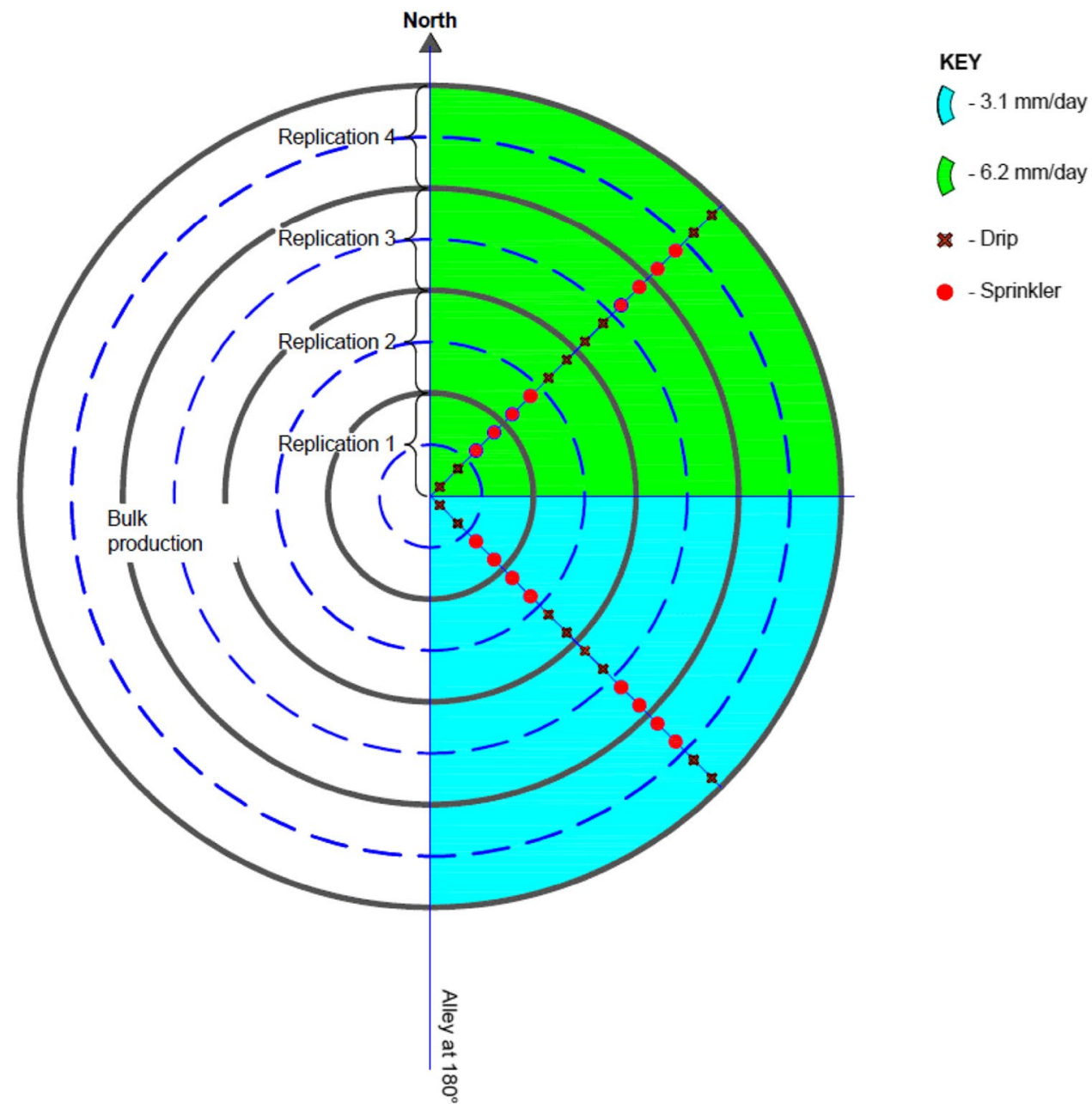

Study 2: $3.1 \mathrm{~mm} /$ day irrigation capacity.

1. MDI-Apply $25 \mathrm{~mm}$ every 8 days.

2. LESA-apply $25 \mathrm{~mm}$ every 8 days.

Irrigations were triggered whenever soil water reached $60 \%$ of plant available water in the top $1.2 \mathrm{~m}$ of the soil profile measured using neutron attenuation, but irrigation frequency was limited by irrigation capacity. In case a rainfall of more than $20 \mathrm{~mm}$ was received, irrigation was postponed. Nozzle flow rate was confirmed using the Spot-on device (Innoquest, Inc., Woodstock, IL). Study 2 received only $57 \%$ of the total irrigation received by Study 1, i.e., 356 versus $203 \mathrm{~mm}$.

\section{Mobile drip irrigation system}

The design objectives of our Study 2 were to overcome problems of earlier MDI designs including emitter clogging, non-uniform water application and precise positioning of the drip line to minimize interaction with crop canopy. The desired characteristics were: (1) uniform application of water with high application efficiency by reducing evaporation losses from the soil and plant canopy, and minimizing potential for runoff, (2) installation of appropriate filtration system to prevent clogging, (3) installation of a dual application system that could be easily switched between spray nozzles and MDI, (4) minimization of the drag on the center pivot by optimizing drip line length and emitter flow rate, (5) to ensure precise positioning of the drip line with minimum interference to the plants by circular planting, (6) to minimize potential for runoff, and (7) to allow for reversing of the center pivot without kinking and tangling of the drip line in the crop canopy. A four span center pivot with a flow rate of $45.4 \mathrm{~m}^{3} / \mathrm{h}$ was modified to have two banks of 13 in-canopy drops for LESA and 13 MDI lateral in each span with a $50 \mathrm{~mm}$ PVC submain, and a 2" flow meter to each zone as shown in Fig. 2. LESA (LESA) and MDI were randomly assigned to each span. The system was operated at a pressure of $90 \mathrm{kPa}$ at the pivot point. For each irrigation event, $25 \mathrm{~mm}$ was applied. 


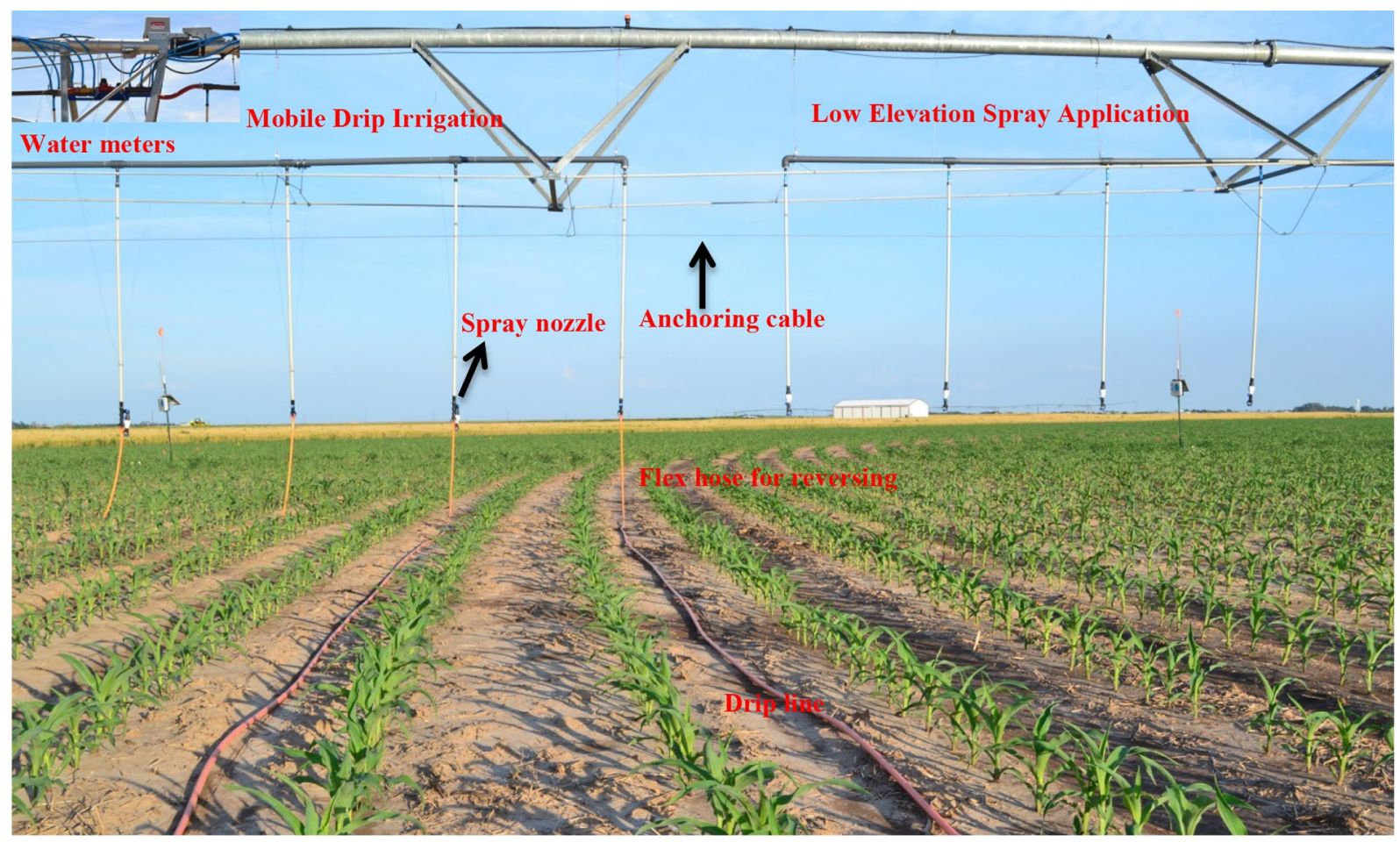

Fig. 2 A span of a center pivot retrofitted with mobile drip irrigation at the Kansas State University Southwest Research and Extension Center near Garden City Kansas

Mobile drip irrigation hydraulic design involved determining a lateral length that minimized friction losses and matched flow rate of the sprinkler nozzle at the same radial distance from the pivot point. The length of the drip lines increased with distance from the pivot point as would a center pivot nozzle package as shown in Table 1. Nozzle flow rate and pressure requirement at radial distance $r$ from the pivot point were estimated using Eqs. 1 and 2:

$q_{\text {nozzle }}=\frac{2 r S_{d}}{R^{2}} Q_{\mathrm{s}}$

$P_{r}=P_{\text {end noz }}+H_{\text {end to } r}+\Delta H_{\text {end to } r}$

where $q_{\text {nozzle }}$ is the nozzle flow rate at radial distance $r$ $\left(\mathrm{m}^{3} / \mathrm{h}\right), r$ is the radial distance from the pivot point along the pivot lateral (m), $S_{d}$ is the nozzle spacing (m), $Q_{\mathrm{s}}$ is the system flow rate $\left(\mathrm{m}^{3} / \mathrm{h}\right), R$ is the length of the pivot lateral (m), $P_{r}$ is the pressure at radial distance $r$ from the pivot point $(\mathrm{kPa}), P_{\text {end noz }}$ is the pressure requirement of the end nozzle $(\mathrm{kPa}), H_{\text {end to } r}$ is the friction losses estimated using Hazen-William equation from the end of the pivot lateral to a point at a radial distance $r(\mathrm{~m}), \Delta H_{\text {end to } r}$ is the head change due to differences in elevation $(\mathrm{m})$ between the end of the lateral and a point a distance $r$ from the pivot point, on a flat field this term tends to zero.

The drip line used in this Study was pressure compensating (DripNet PC, NETAFIM Inc., Fresno CA) with the following attributes: (1) $1.14 \mathrm{~mm}$ wall thickness, (2) $15 \mathrm{~mm}$ inside diameter, (3) pressure range with constant flow 41-400 kPa, (4) emitter flow rate $3.79 \mathrm{l} / \mathrm{h}$, and (4) emitter spacing $15.24 \mathrm{~cm}$, (5) minimum filtration 80 mesh (120 mesh used in our study), and (6) $K_{d}$ of 0.85 , and emitter discharge exponent $X$ of 0 . Drip line length at a given radial distance $r$ was estimated using Eq. 3:

$q_{1}=\frac{l}{S_{\mathrm{e}}} \times \frac{q_{\mathrm{e}}}{1000}=\frac{n_{\mathrm{e}} q_{\mathrm{e}}}{1000}$

where $q_{1}$ is the lateral flow rate $\left(\mathrm{m}^{3} / \mathrm{h}\right)$ obtained from Eq. 1, $l$ is the lateral length $(\mathrm{m}), q_{\mathrm{e}}$ is the emitter flow rate $(1 / \mathrm{h}), S_{\mathrm{e}}$ is the emitter spacing $(\mathrm{m}), n_{\mathrm{e}}$ is the number of emitters and 1000 is a conversion factor.

The design goal of micro-irrigation is to achieve high application uniformity. For pressure compensating drip line, the emitter discharge exponent $X$ is approximately zero and, therefore, emitter discharge rate does not vary with pressure beyond the minimum threshold pressure as shown in Eq. 4:

$q_{e}=K_{d} \times P^{X}$

where $K_{d}$ is a constant that varies with emitter model and units used in Eq. 4, and $P$ is drip line operating pressure $(\mathrm{kPa})$. However, when the pressure in the lateral drops below the minimum threshold pressure, the drip line loses pressure compensating capabilities. Pressure in the MDI system was kept above $41 \mathrm{kPa}$ as shown in Table 1 implying that emitter 
Table 1 Hydraulic characteristics of mobile drip irrigation system installed at the Kansas State University Southwest Research and Extension Center (SWREC) near Garden City Kansas

\begin{tabular}{|c|c|c|c|c|c|}
\hline & Outlet no. & $\begin{array}{l}\text { Distance to } \\
\text { pivot point } \\
\text { (m) }\end{array}$ & $\begin{array}{l}\text { Flow } \\
\text { needed } \\
\left(\mathrm{m}^{3} / \mathrm{h}\right)\end{array}$ & $\begin{array}{l}\text { Nozzle } \\
\text { pressure } \\
(\mathrm{kPa})\end{array}$ & $\begin{array}{l}\text { Drip line } \\
\text { length } \\
(\mathrm{m})\end{array}$ \\
\hline \multirow[t]{10}{*}{ Span 1} & 1 & 10.67 & 0.05 & 123.42 & 2.13 \\
\hline & 2 & 12.19 & 0.06 & 123.00 & 2.44 \\
\hline & 3 & 13.72 & 0.07 & 124.11 & 2.74 \\
\hline & 4 & 15.24 & 0.07 & 123.76 & 3.05 \\
\hline & 5 & 16.76 & 0.08 & 123.55 & 3.35 \\
\hline & 6 & 18.29 & 0.09 & 123.35 & 3.35 \\
\hline & 7 & 19.81 & 0.09 & 123.21 & 3.66 \\
\hline & 8 & 21.34 & 0.10 & 123.14 & 3.96 \\
\hline & 9 & 22.86 & 0.11 & 123.14 & 4.27 \\
\hline & 10 & 24.38 & 0.12 & 123.21 & 4.57 \\
\hline \multirow[t]{14}{*}{ Span 2} & 35 & 62.48 & 0.30 & 120.66 & 11.89 \\
\hline & 36 & 64.01 & 0.30 & 120.59 & 12.19 \\
\hline & 37 & 65.53 & 0.31 & 120.59 & 12.50 \\
\hline & 38 & 67.06 & 0.32 & 120.59 & 12.80 \\
\hline & 39 & 68.58 & 0.33 & 120.73 & 13.11 \\
\hline & 40 & 70.10 & 0.33 & 119.42 & 13.41 \\
\hline & 41 & 71.63 & 0.34 & 119.69 & 13.72 \\
\hline & 42 & 73.15 & 0.35 & 119.97 & 14.02 \\
\hline & 43 & 74.68 & 0.35 & 120.31 & 14.33 \\
\hline & 44 & 76.20 & 0.36 & 119.21 & 14.63 \\
\hline & 45 & 77.72 & 0.37 & 119.69 & 14.94 \\
\hline & 46 & 79.25 & 0.38 & 118.73 & 15.24 \\
\hline & 47 & 80.77 & 0.38 & 119.21 & 15.54 \\
\hline & 48 & 82.30 & 0.39 & 119.07 & 15.85 \\
\hline \multirow[t]{13}{*}{ Span 3} & 49 & 83.82 & 0.40 & 118.93 & 16.15 \\
\hline & 50 & 85.34 & 0.41 & 118.38 & 16.46 \\
\hline & 51 & 86.87 & 0.41 & 119.07 & 16.76 \\
\hline & 52 & 88.39 & 0.42 & 118.31 & 17.07 \\
\hline & 53 & 89.92 & 0.43 & 117.76 & 17.07 \\
\hline & 54 & 91.44 & 0.43 & 118.59 & 17.37 \\
\hline & 55 & 92.96 & 0.44 & 118.04 & 17.68 \\
\hline & 56 & 94.49 & 0.45 & 117.49 & 17.98 \\
\hline & 57 & 96.01 & 0.46 & 118.52 & 18.29 \\
\hline & 58 & 97.54 & 0.46 & 118.11 & 18.59 \\
\hline & 59 & 99.06 & 0.47 & 117.76 & 18.90 \\
\hline & 60 & 100.58 & 0.48 & 117.49 & 19.20 \\
\hline & 61 & 102.11 & 0.49 & 117.28 & 19.51 \\
\hline \multirow[t]{9}{*}{ Span 4} & 89 & 144.78 & 0.69 & 112.87 & 27.74 \\
\hline & 90 & 146.30 & 0.70 & 112.73 & 28.04 \\
\hline & 91 & 147.83 & 0.70 & 112.66 & 28.35 \\
\hline & 92 & 149.35 & 0.71 & 112.66 & 28.65 \\
\hline & 93 & 150.88 & 0.72 & 112.66 & 28.96 \\
\hline & 94 & 152.40 & 0.72 & 111.35 & 29.26 \\
\hline & 95 & 153.92 & 0.73 & 111.56 & 29.57 \\
\hline & 96 & 155.45 & 0.74 & 111.76 & 29.87 \\
\hline & 97 & 156.97 & 0.75 & 112.04 & 30.18 \\
\hline
\end{tabular}

Table 1 (continued)

\begin{tabular}{rllll}
\hline Outlet no. & $\begin{array}{l}\text { Distance to } \\
\text { pivot point } \\
(\mathrm{m})\end{array}$ & $\begin{array}{l}\text { Flow } \\
\text { needed } \\
\left(\mathrm{m}^{3} / \mathrm{h}\right)\end{array}$ & $\begin{array}{l}\text { Nozzle } \\
\text { pressure } \\
(\mathrm{kPa})\end{array}$ & $\begin{array}{l}\text { Drip line } \\
\text { length } \\
(\mathrm{m})\end{array}$ \\
\hline 98 & 158.50 & 0.75 & 110.94 & 30.48 \\
99 & 160.02 & 0.76 & 111.56 & 30.48 \\
100 & 161.54 & 0.77 & 110.59 & 30.78 \\
101 & 163.07 & 0.78 & 111.01 & 31.09 \\
102 & 164.59 & 0.78 & 110.59 & 31.70 \\
\hline
\end{tabular}

flow rate was maintained at $3.79 \mathrm{l} / \mathrm{h}$. Although it is easier to maintain uniformity with pressure compensating emitters, it important to minimize the pressure requirements of the system which includes the friction losses along the lateral but also adequate pressure at the distal end of the pivot must be maintained in order to keep the pressure above the minimum regulated/threshold pressure for the pressure compensating emitters.

The friction loss gradient along the MDI drip lines was checked using a combination of Darcy-Weisbach and Blasius equations expressed as Eqs. 5 to 7 (Keller and Bliesner 2001):

$J=7.83 \times 10^{7} \times \frac{q_{l}^{1.75}}{D^{4.75}}\left[\frac{S_{e}-f_{e}}{S_{e}}\right]$

$J^{\prime}=J \times\left[\frac{S_{e}-f_{e}}{S_{e}}\right]$

$f_{e}=k_{d} \frac{v^{2}}{2 g}$

where $J$ is the friction loss gradient $(\mathrm{m} / 100 \mathrm{~m}), q_{l}$ is the lateral discharge $(1 / \mathrm{s}), D$ is the lateral diameter $(\mathrm{mm}), f_{e}$ is the equivalent length of lateral due emitter head loses (m), $v$ is the velocity of flow $(\mathrm{m} / \mathrm{s}), g$ is the acceleration due to gravity $\left(\mathrm{m} / \mathrm{s}^{2}\right)$ and all other terms are as defined previously.

The ends of the drip lines were fitted with threaded end caps for easy flushing. The purpose of the flex tube between the nozzle drop and drip line was to minimize kinking in the drip line when the direction of travel of the center pivot was reversed. To minimize flex and movement, the PVC drops were connected to a 16 gauge wire that ran across two towers as shown in Fig. 2. The drops were also supported with cables connected to opposite ends of the truss rods. To ensure germination, fertilizer and herbicide incorporation in dry years, a spray nozzle with a $69 \mathrm{kPa}$ pressure regulator was installed every $3 \mathrm{~m}$ with valves that allowed the choice of drip or sprinkler irrigation. Pressure gauges were installed at the head control and pivot point to monitor clogging, i.e., 
an increase in pressure coupled with a reduction in flow indicated clogging. A decrease in pressure accompanied by an increase in flow may indicate drip line tubing leakage.

\section{Soil water measurement}

Soil water evaporation was measured starting at 51 days after planting (V8) using mini-lysimeters placed within the variably wetted MDI plots and in uniformly wetted LESA plots. The layout and dimensions of the mini-lysimeters are shown in Fig. 3a and b. Mini-lysimeters consisted of stainless steel rings (Eijkelkamp, North America, Morrisville, NC) with a diameter of approximately $76 \mathrm{~mm}$ and length of $100 \mathrm{~mm}$. The purpose of the PVC sleeve was to minimize lateral heat flux but maximize vertical heat flux. Lysimeters were installed approximately $24 \mathrm{~h}$ after the irrigation event by taking an undisturbed soil core using the stainless steel rings and capping the sample at the bottom before placing it in the PVC sleeve (Fig. 4). The reason for collecting the undisturbed soil core after an irrigation event and not before was to allow lateral redistribution to occur especially under MDI, to allow the soil to drain to near field capacity and

A

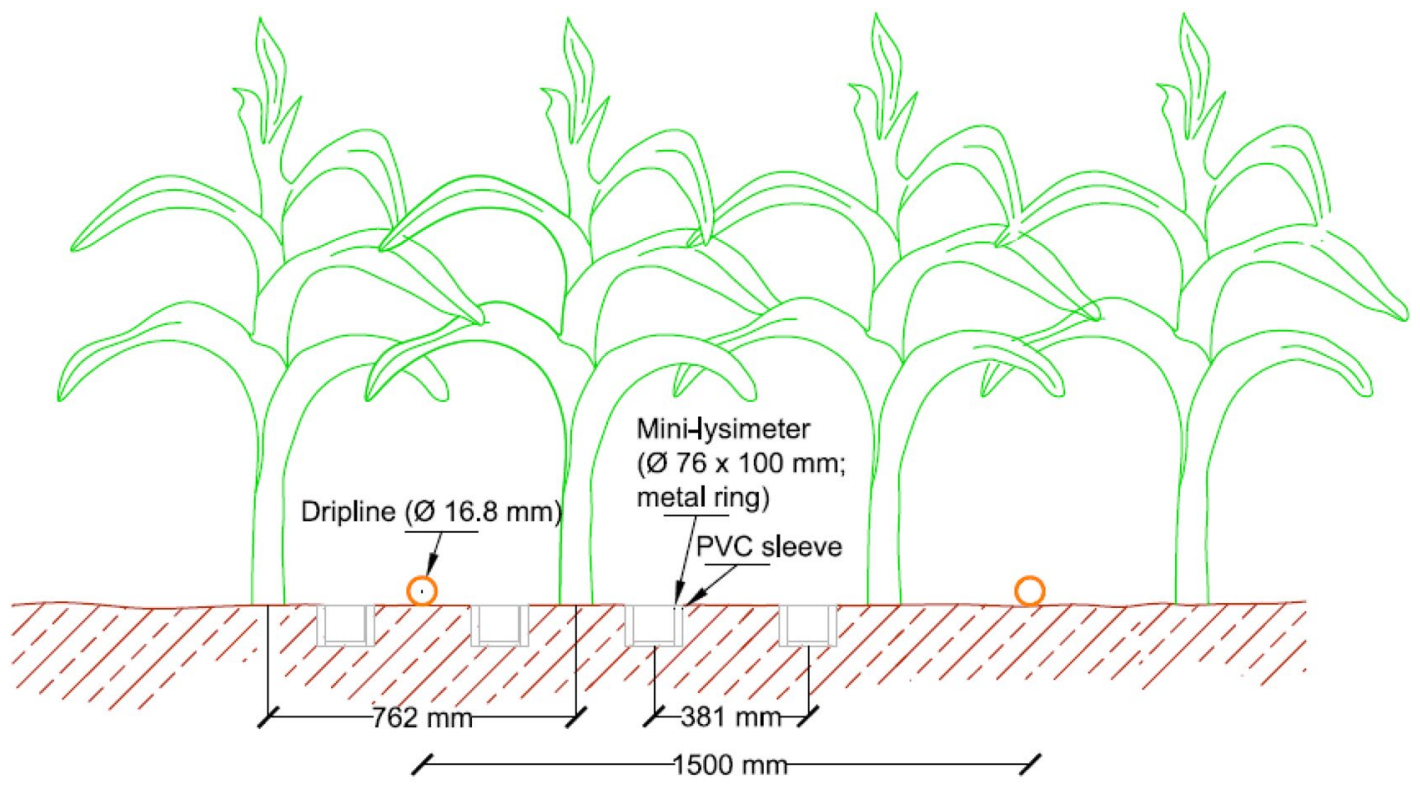

B

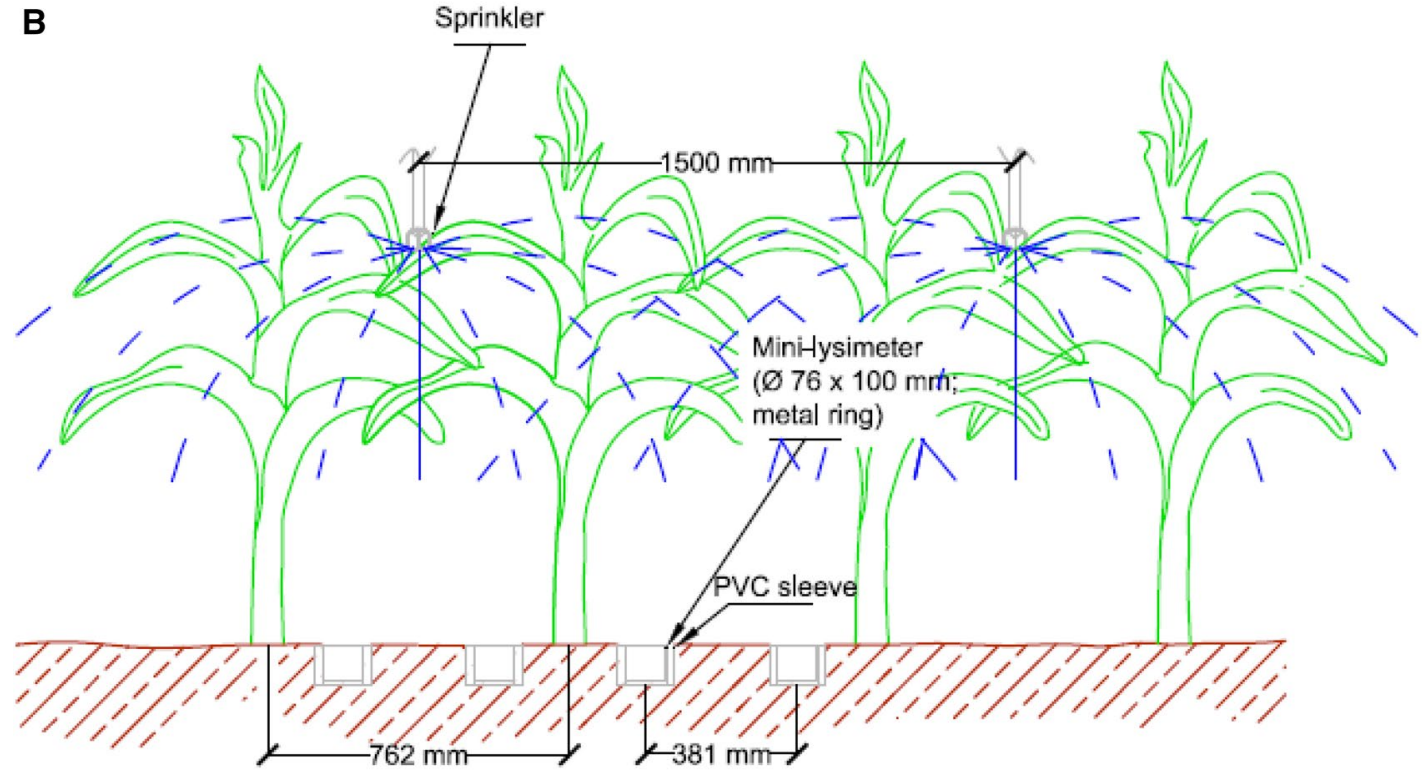

Fig. 3 Schematic layout of mini-lysimeters used to measure soil water evaporation under mobile drip irrigation (a) and Low Elevation Spray Application (b) at the Kansas State University Southwest Research-Extension Center near Garden City, Kansas 
to eliminate potential for saturating the mini-lysimeter. The changes in mini-lysimeter weight were recorded every $24 \mathrm{~h}$ using a precision scale (Adam Equipment Inc, Oxford, CT) and converted to evaporation rates. The assumption was the changes in weight were due to water lost by evaporation. There were two mini-lysimeters between the non-wetted corn rows and two lysimeters in the wetted row under MDI (Fig. 3). Each set of four mini-lysimeters in MDI and LESA plots was replicated four times following the randomized complete block design in Fig. 1 under the $6.2 \mathrm{~mm}$ irrigation capacity study. In each replication, soil water evaporation rates were calculated as the average of measurements from the four mini-lysimeters. The measurements were repeated three times 51, 52 and 53 days after planting (Fig. 3a, b). The results were analyzed using the GLIMMIX procedure in SAS Studio 3.6 (SAS Institute Inc 2016).

The effect of $152 \mathrm{~cm}$ lateral spacing on soil water redistribution was evaluated by Kriging (interpolating) soil water measurements made using neutron attenuation to a depth of $2.4 \mathrm{~m}$ in a transect of five neutron probe access tubes placed $38 \mathrm{~cm}$ apart. The GS + software (Gamma Design Software, LLC, Plainwell, Michigan) was used to implement kriging of soil water measurements. The kriging parameters were: nugget ( 0), sill (0.002) and range (1.86) $\mathrm{m}$.
Soil water measurements were taken weekly using a neutron probe (CPN 503DR, CPN International, Concord, California) at $0.3 \mathrm{~m}$ depth increments up to $2.4 \mathrm{~m}$ depth. Seasonal crop water use or evapotranspiration (ET) was estimated from a water balance expressed as Eq. 8:

$\mathrm{ET}=I+P+C-R-(\mathrm{SW} 1-\mathrm{SW} 2)-D$

where $I$ is the irrigation $(\mathrm{mm}), P$ is the precipitation $(\mathrm{mm})$, $\mathrm{C}$ is the upward capillary flux $(\mathrm{mm})$ assumed negligible due to very deep water table, $R$ is the runon or runoff assumed negligible (mm), SW1 is the first neutron probe soil water measurements (taken close to emergence), and SW2 is the final neutron probe soil water measurements taken at physiological maturity $(\mathrm{mm})$, and $D$ is the deep drainage estimated based on Stone et al. (2011). Water productivity was estimated as the ratio of grain yield to seasonal ET $\left(\mathrm{kg} / \mathrm{m}^{3}\right)$.

\section{Statistical analysis}

Statistical analysis was implemented using the PROC GLIMMIX procedure in SAS studio (http://www.sas.com/ en_us/software/foundation/studio.html). Statistical tests were conducted at a $5 \%$ level of significance.

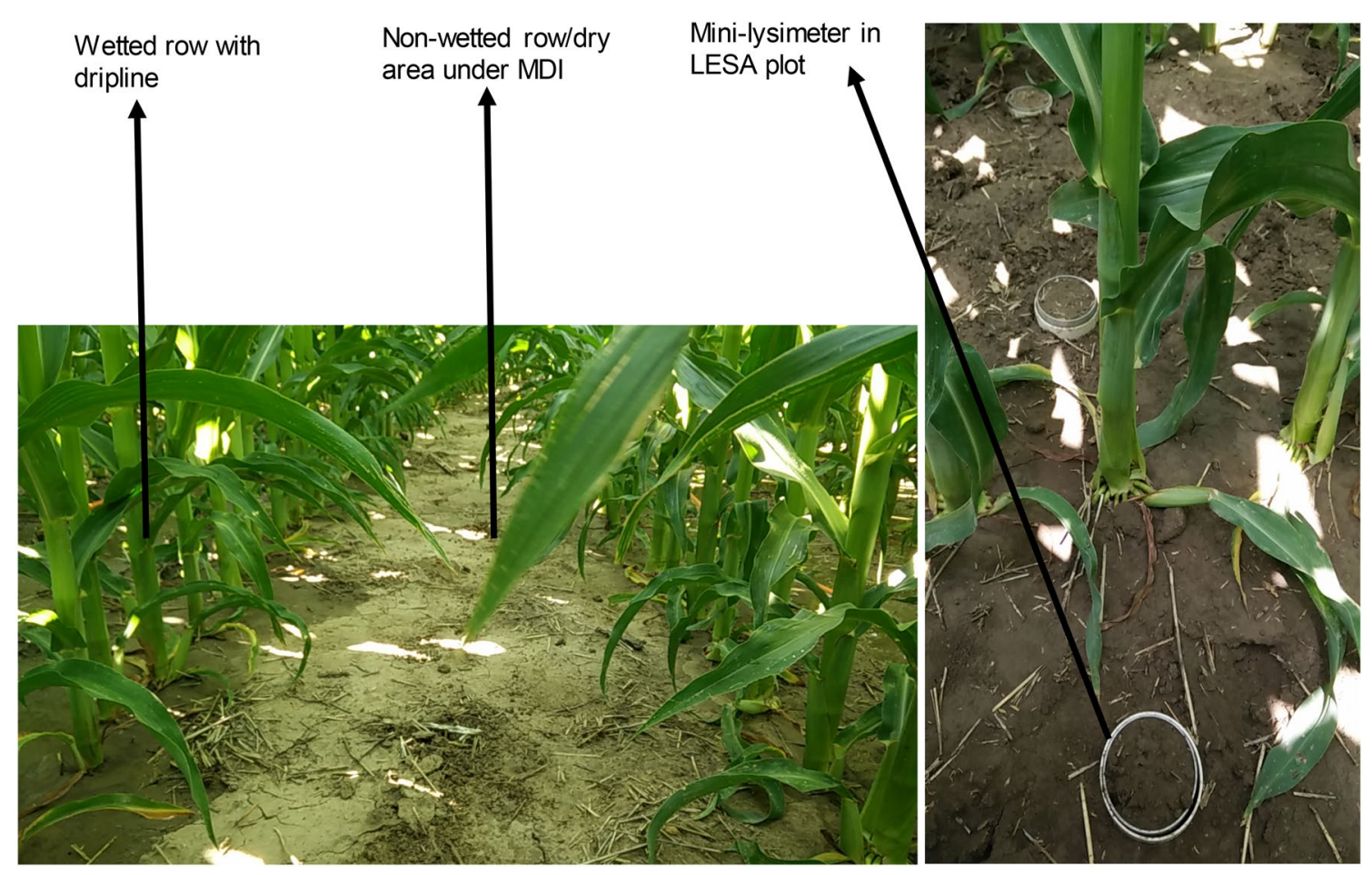

Fig. 4 Mobile drip irrigation plot showing wetted and non-wetted areas and mini-lysimeters showing stainless steel ring holding the soil core and PVC sleeve used to minimize lateral heat flow in a low elevation spray application plot at the Kansas State University Southwest Research-Extension Center near Garden City, Kansas 


\section{Results and discussion}

\section{Weather}

Offseason rainfall from November 2014 to April 2015 totaled $43.4 \mathrm{~mm}$ which was $20 \%$ less than normal during the same period. Rainfall during the 2015 growing season from May 1 to October 31 exceeded the long-term average in the same period from 1950 to 2014 as shown in Fig. 5 . The 2015 summer growing season rainfall exceeded the long-term average by $107 \mathrm{~mm}$. Figure 3 shows monthly rainfall totals and cumulative rainfall and ET totals during the 2015 growing season. June was drier than normal and corresponded to corn vegetative growth stages V5 to V16. Above normal rainfall in May of 2015 ensured sufficient soil water to buffer the crop between irrigation or rainfall events. Also, the above normal rainfall at tasseling in July minimized potential for yield reduction even under limited well capacity of $3 \mathrm{~mm} /$ day. August was wetter than normal, thus contributing substantially to crop water needs during early grain fill. Drier than normal conditions occurred during later grain fill corresponding to growth stages R3 to R5 which was drier than normal during the month of September. It can also be seen from Fig. 5 that even under above normal rainfall years, reference ET greatly exceeded seasonal rainfall which underscores the need for irrigation if high yield potential is to be attained.

Average seasonal maximum temperature was slightly lower than normal $\left(28.3\right.$ versus $29.4{ }^{\circ} \mathrm{C}$ ), while average growing season minimum temperature was slightly above normal (14.2 versus $14.1^{\circ} \mathrm{C}$ ). Solar radiation on average was higher during the vegetative growth stages and anthesis and gradually decreased during later grain fill. Vapor pressure deficit did not show any particular trends during the growing season with a few spikes in June and late July. There was no particular trend in wind speeds but maximum daily wind speeds ranged between 5 and $20 \mathrm{~m} / \mathrm{s}$, while average daily wind speeds ranged between 1.5 to $7 \mathrm{~m} / \mathrm{s}$.

\section{Soil water measurements}

\section{Soil water evaporation}

Results indicate that soil water evaporation was significantly lower $(p<0.05)$ under MDI, compared to LESA, on average by $35 \%$ (Fig. 4). The differences could be attributed to the reduced surface area wetted by the drip line compared to the sprinklers (Fig. 4). Soil water evaporation measurements were done starting 51 days after planting on 7/10/2015, $7 / 11 / 2015$ and 7/12/2015 when corn was at growth stage V8. LAI was not measured on same days as soil water evaporation measurements. But LAI measurements were made before and after soil water evaporation measurements on 6/27/2015 (MDI: $1.6 \pm 0.17$ and LESA $1.7 \pm 0.23$ ) and on 7/27/2015 (MDI: $3.4 \pm 0.09$ and LESA $3.5 \pm 0.09$ ). At the time of soil water evaporation measurements, the canopy was not completely closed with some radiation still directly reaching the ground surface (Fig. 4). Climatic conditions during soil water evaporation measurements were: average wind speed of $3.9 \mathrm{~m} / \mathrm{s}$, maximum wind speed of $11.8 \mathrm{~m} / \mathrm{s}$, average temperature of $36.3{ }^{\circ} \mathrm{C}$, relative humidity of $57 \%$, and solar radiation of $29.3 \mathrm{MJ} / \mathrm{m}^{2}$ (http://mesonet.k-state.edu/ weather/historical/\#!). These climatic conditions indicate that the atmospheric evaporative demand was high during soil
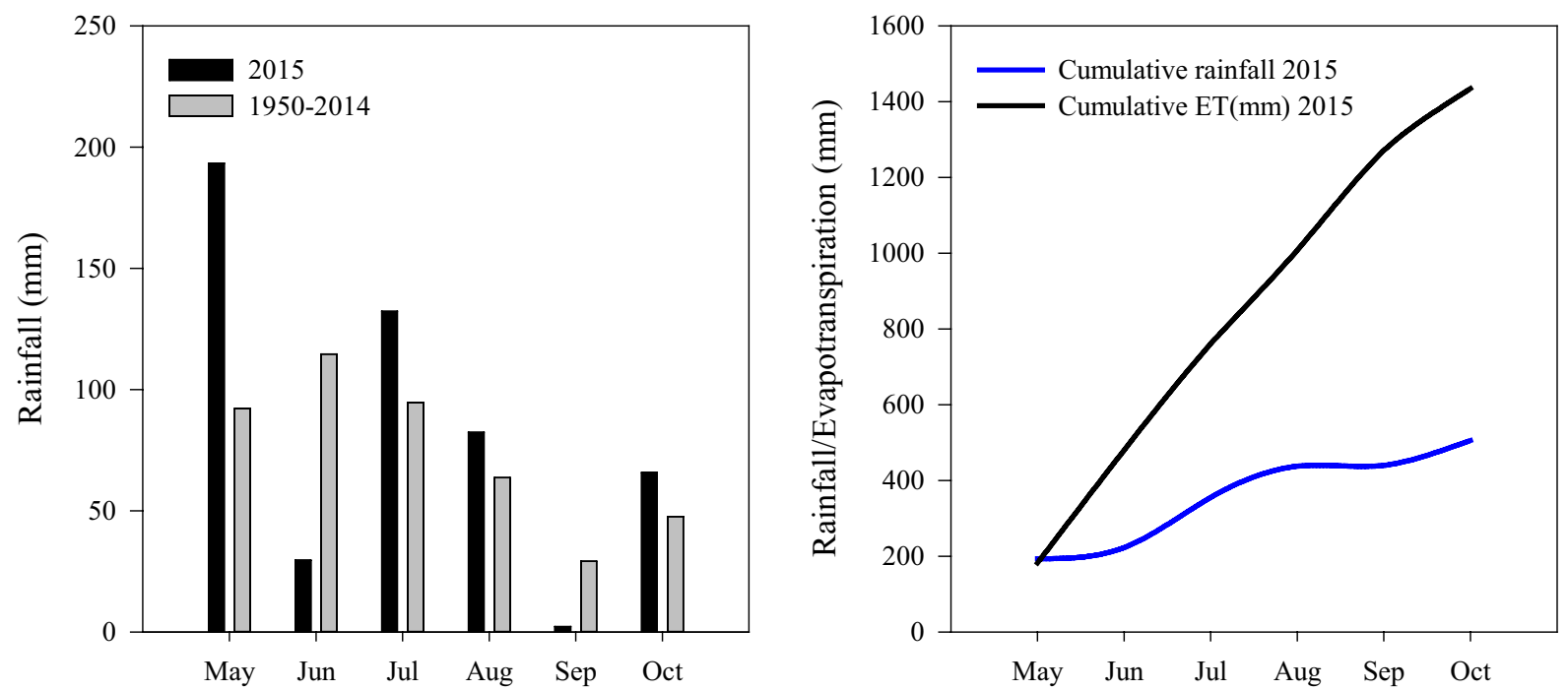

Fig. 5 Monthly and cumulative rainfall and reference evapotranspiration during the corn growing season at Kansas State University SWREC near Garden City, Kansas 
water evaporation measurements with grass reference ET averaging $8.7 \mathrm{~mm} /$ day over the 3 days. Such weather conditions are not uncommon in the Southern Great Plains during the corn growing season, particularly in July. Under these conditions, precision application of water using technologies such as MDI could reduce non productive water losses such as soil water evaporation. Also, reduced instantaneous application rate with MDI compared to LESA could also have the advantage of reducing runoff or surface redistribution.

From field observations, areas not wetted on the surface had a higher albedo compared to areas that were wetted by the drip lines or spray nozzles (Fig. 4). The total surface area wetted under LESA was larger than MDI explaining the differences in observed soil water evaporation rates. We observed that the wetted width under a drip line was approximately $76 \mathrm{~cm}$ and occurred only between plant rows where the drip line was located compared to LESA that wetted the entire surface between crop rows. Future studies need to quantity the partitioning of evapotranspiration into evaporation and transpiration under MDI and LESA, particularly early in the season from VE to V8 when a significant amount of water is lost to evaporation. Another aspect that needs further research is the effect of residue cover on reduction of soil water evaporation under MDI. During the 2015 cropping season, there was no residue cover since the field had been tilled several times before planting. Combined benefits of residue cover and precision water application with MDI have the potential of improving water productivity under limited water supplies.

Also, future research could explore how the reduction in soil water evaporation or latent heat affects other components of the energy balance including sensible heat, soil heat flux under MDI since the net radiation reaching the same surface is not expected to change irrespective of irrigation application method.

There is limited literature on comparison of soil water evaporation losses under MDI. Application methods that would be closest to MDI are LEPA and SDI; therefore, inferences will be made to LEPA and SDI. Schneider (2000) identified wetted soil water evaporation as one of the major water loss pathways for LEPA and sprinkler irrigation with more potential loss of soil water under sprinkler which wet the entire soil surface compared to $1 / 2$ to $1 / 3$ wetted soil surface under LEPA. The wetted area of MDI could be potentially lower than LEPA. Evett et al. (2005) noted that water loss from the soil profile through evaporation is a significant contributor to irrigation inefficiency and irrigation methods such as drip can minimize this water loss by up to $76 \mathrm{~mm}$ over a growing season, particularly before full canopy cover. Evett et al. (2005) also noted that limited soil cooling from soil water evaporation associated with drip irrigation could benefit crops such as sorghum and cotton that need warm soil temperatures for germination and, consequently, earlier maturity. Our results indicate a daily average difference of
$1 \mathrm{~mm}$ between MDI and LESA during the V8 growth stages; it is plausible that the difference could be higher during early vegetative and negligible after full canopy closure. Colaizzi et al. (2006) reviewed production under various irrigation methods in the US High Plains and reported that LEPA and to a greater extent SDI partitioned more water to transpiration relative to spray under low irrigation applications, implying that there was less soil water loss under LEPA and SDI compared to sprinkler applications. MDI which applies water in a similar way to LEPA and SDI (partial wetting of soil) could enhance water productivity by increasing transpiration and reducing evaporation losses (Fig. 6).

\section{Soil water redistribution}

Regarding soil water redistribution beneath the soil surface, soil water was well distributed between corn rows and was the highest mid-point between the two drip lines spaced $152 \mathrm{~cm}$ apart at a depth of approximately 50-70 cm (Fig. 7). Before irrigation on June 30th, the non-wetted row was dry; after irrigation on July 1st, there was lateral redistribution in the top $1.0 \mathrm{~m}$ of soil profile expanding from the fringes of the wetted bulb of the drip line. Below $1.0 \mathrm{~m}$, the flow was mainly vertical as shown in Fig. 7. These results indicate that drip line spacing of $152 \mathrm{~cm}$ is adequate for silt loam soils of southwest Kansas to ensure that all plants have equal access to the water. This spacing could also enhance precipitation capture and storage by enhancing infiltration rates in the dry rows due to low antecedent soil water content prior to a rainfall event. In contrast, soil water redistribution under

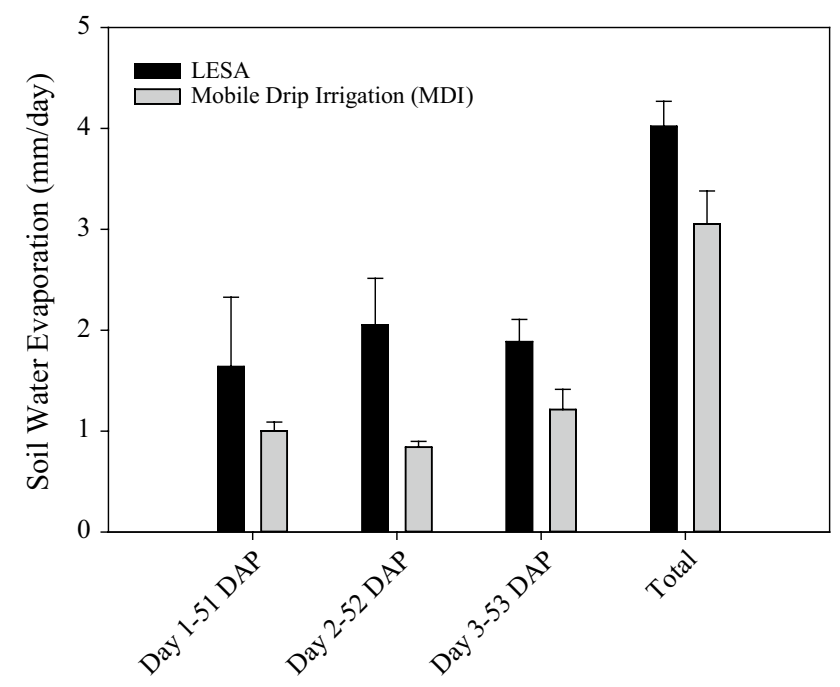

Fig. 6 Comparison of soil water evaporation under MDI and low elevation spray application on three different days during corn vegetative growth stage V8 starting at 51 days after planting (DA) during the 2015 cropping season at the Kansas State University Southwest Research-Extension Center, near Garden City, Kansas 
Fig. 7 Soil water redistribution under Mobile Drip Irrigation (MDI) for $6.2 \mathrm{~mm} /$ day irrigation system capacity measured using neutron attenuation technique before irrigation (7A) on June 30,2015 and after irrigation (7B) on July 01,2015 at the Kansas State University SWREC near Garden City
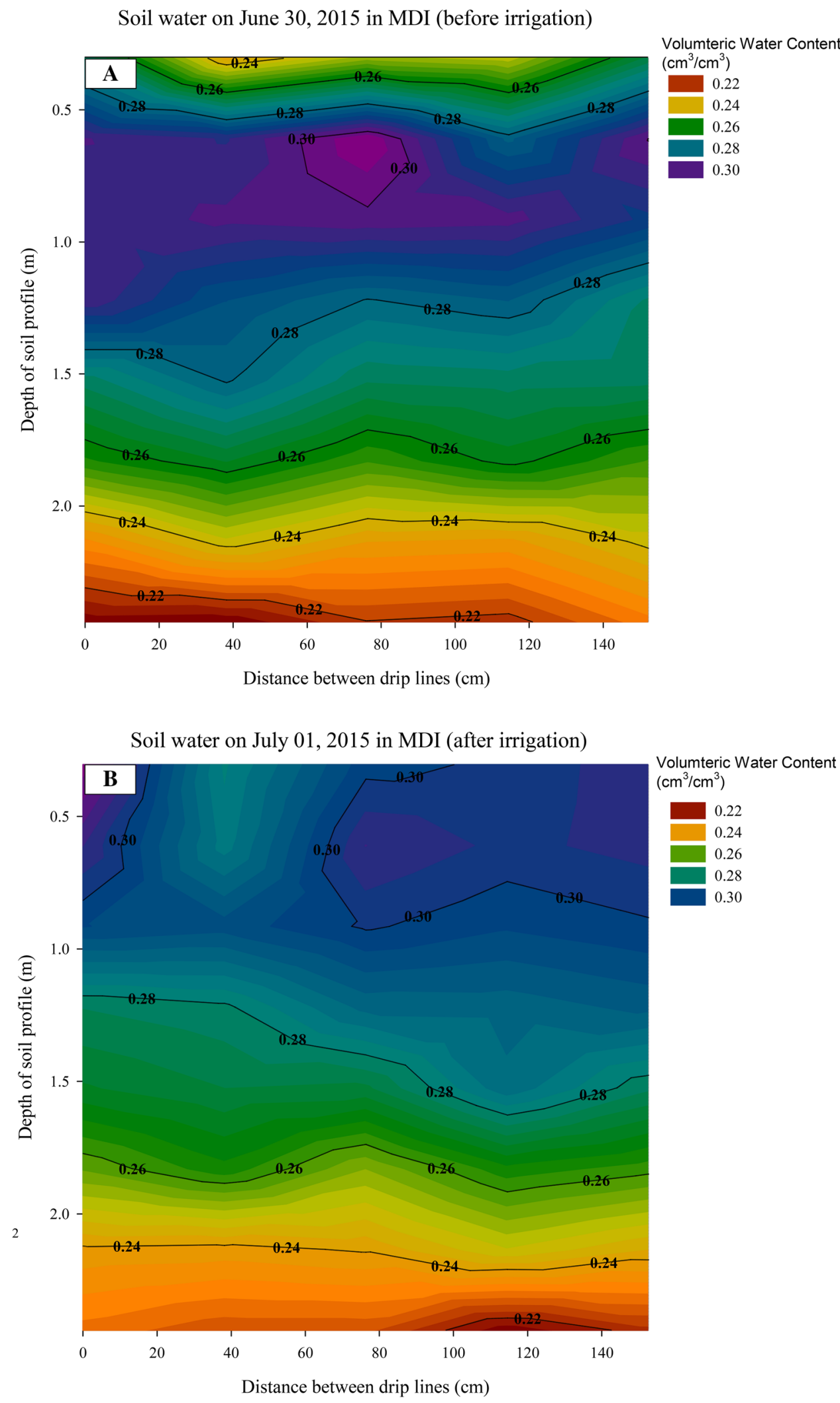

LESA was uniform in the top $0.5 \mathrm{~m}$ with predominately vertical redistribution due to the uniform wetting pattern of sprinklers (Fig. 8).
Several investigators have assessed soil water redistribution patterns from drip irrigation or point source emitters, with the goal to gain better understanding of lateral and 
vertical movement of water and salts from a drip line. Levin et al. (1979) reported that in sandy soil the wetting pattern was more vertically elongated compared to lateral movement, while Bar-Yosef and Sheikholslami (1976) reported more horizontal elongation in clay soil. Hachum et al. (1976) reported that water redistribution was more or less uniform in all directions in a silt loam soil. The soil type at our study site was a Ulysses silt loam and our results in Fig. 7 indicate redistribution in both horizontal and vertical direction which agrees with the findings of Hachum et al. (1976). Soil water redistribution patterns are also impacted by emitter or point source application rates. Mostaghimi et al. (1982) reported that on a silt loam soil, a $1.0 \mathrm{l} / \mathrm{h}$ drip emitter tended to produce more lateral water movement compared to a $4.0 \mathrm{l} / \mathrm{h}$ emitter which resulted in more vertical water movement. Amir and Dag (1993) compared lateral and longitudinal wetting patterns of low energy moving emitters and reported high instantaneous application rates resulted in more uniform application with wide width but with reduced depth. Schwank and Hanson (2006) reported that under field conditions with active crop growth, soil water redistribution might be minimal due to root water extraction. It appears that for MDI, drip line with high discharge rates might be advantageous for several reasons including a shorter drip line length that are dragged by the center pivot, better uniformity, reduced potential for deep drainage especially on fine textured soils; low instantaneous application rates may be desirable on coarse textured soils.

\section{End of season soil water}

End-of-season soil water measured at harvest showed that the total soil water in the $2.4 \mathrm{~m}$ soil profile was significantly higher $(p=0.001)$ in MDI compared to LESA in Study 2 at $3.1 \mathrm{~mm} /$ day irrigation capacity (Fig. 9). However, in Study 1 at $6.2 \mathrm{~mm}$ /day irrigation capacity, end-of-season soil water was not significantly different between MDI and LESA or LESA (Fig. 9). Figure 9 also shows that MDI was able to store more water at deeper depth compared to LESA. In Study 2, plant available water at physiological maturity under MDI was twice that under LESA (Fig. 9). We can conclude that storage efficiency was higher under MDI, particularly under low well capacity. It was also observed that plots under MDI did not have deep wheel tracks associated with center pivot sprinkler irrigation systems as shown in Fig. 10.

\section{Biophysical measurements}

Production variables such as grain yield and yield components presented in this paper from a single cropping season are not sufficient to adequately answer the question of whether MDI has a significant effect on grain yield and yield components. Production variable data from several years with different weather conditions will be needed to conclusively evaluate the effect of application method on yield and yield components. For completeness, results from biophysical measurements made in 2015 cropping season are presented. LAI measured in the two studies comparing MDI and LESA are shown in Fig. 11; these results indicate no substantial difference in LAI between drip and sprinkler irrigation application methods. Grain yields adjusted to nominal moisture content of $15.5 \%$ ( $\mathrm{kg} / \mathrm{ha}$ ) for Studies 1 and 2 during the 2015 growing season are summarized in Table 2. The effect of irrigation application method (MDI versus LESA) on yield at high $(6.2 \mathrm{~mm} /$ day $)$ and low irrigation capacities $(3.1 \mathrm{~mm} /$ day $)$ was not statistically significant at the $5 \%$ level (Fig. 9). The $p$ were $p=0.37$ and $p=0.67$ for Studies 1 and 2, respectively. This confirms lack of differences in crop growth exhibited by LAI. In Study 1, MDI and LESA nozzles produced yields of 15.6 and $16.0 \mathrm{Mg} /$ ha, respectively. Under Study 2, MDI and LESA nozzles produced yields of 15.2 and $13.8 \mathrm{Mg} / \mathrm{ha}$, respectively. The lack of significant differences in yield could be attributed to the high rainfall received during 2015 growing season at critical growth stages of VT to R5. The total rainfall received during the growing season was $470 \mathrm{~mm}$ which provided $75 \%$ of crop water requirements assuming average corn seasonal crop water use of $625 \mathrm{~mm}$. Annual normal rainfall for the study area is $457 \mathrm{~mm}$. Yield reported in this study is within ranges of corn yields under full irrigation in long term studies that have been reported for western Kansas by Schlegel et al. (2012) and Klocke et al. (2015). Earlier studies on MDI did not observe significant differences in yield but reported potential of the technology to increase water productivity since similar yields as sprinkler irrigation were obtained with less water application (Howell and Phene 1983; Derbala 2003; Olson and Rogers 2007).

Similarly, there were no significant differences in yield components (kernel weight and kernels per ear) within each study as shown in Table 2. Although statistical conclusions cannot be made between the two independent studies, it is worth noting that there were no substantial differences in kernel number per ear at the two irrigation capacities in Studies 1 and 2 despite the fact that Study 2 received only $57 \%$ of the total irrigation received by Study 1, i.e., $356 \mathrm{~mm}$ versus $203 \mathrm{~mm}$ for Studies 1 and 2, respectively. The number of kernels per ear is determined earlier in the season beginning around V6 to V18, while kernel weight is determined by conditions later in the season starting around R1 to R6. The above normal rainfall in July prevented water stress that would have reduced the number of kernels per ear and ear size in both studies. The above normal rainfall in late July and August that corresponded to R1 enabled the potential kernel size to be equally set in both studies. Timely rainfall that matches critical growth stages can have a substantial 
Fig. 8 Soil water redistribution under low elevation spray application (LESA) for $6.2 \mathrm{~mm} /$ day irrigation system capacity measured using neutron attenuation technique before irrigation a on June 30, 2015 and after irrigation b on July 01, 2015 at the Kansas State University SWREC near Garden City
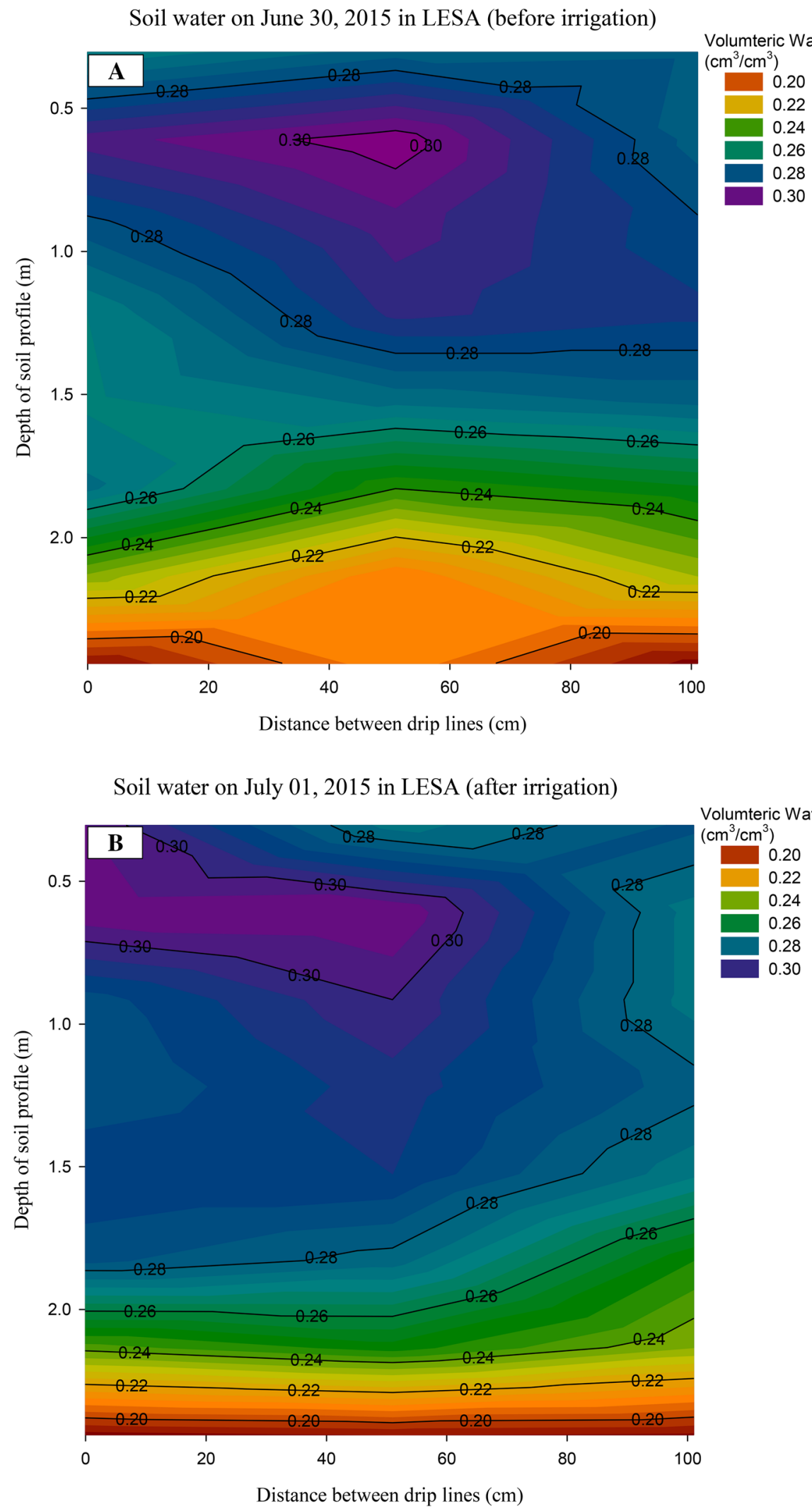
Volumetric soil water conternt $\left(\mathrm{m}^{3} / \mathrm{m}^{3}\right)$ under $6.2 \mathrm{~mm} /$ day IC

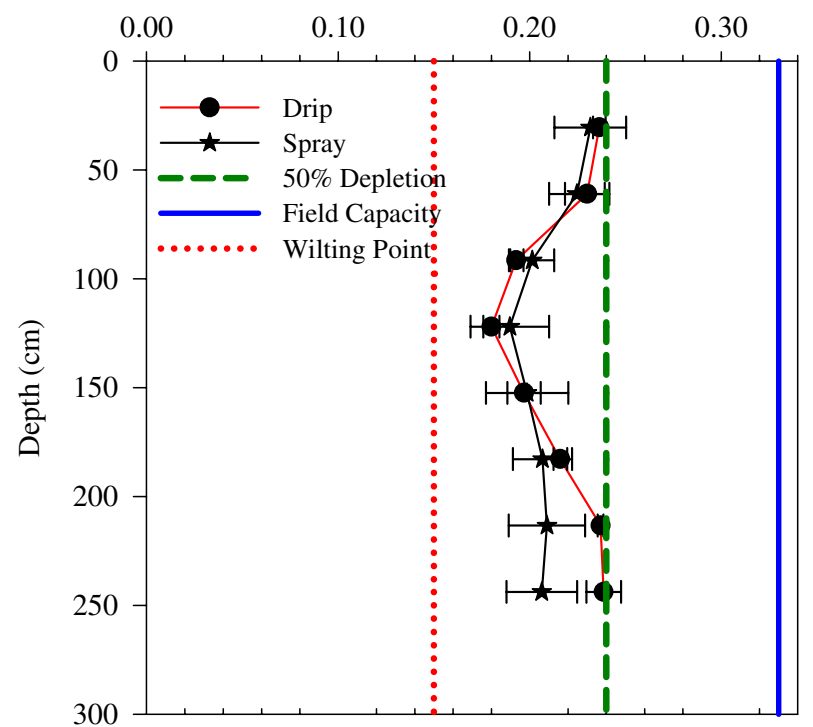

Volumetric soil water conternt $\left(\mathrm{m}^{3} / \mathrm{m}^{3}\right)$ under $3.1 \mathrm{~mm} /$ day IC

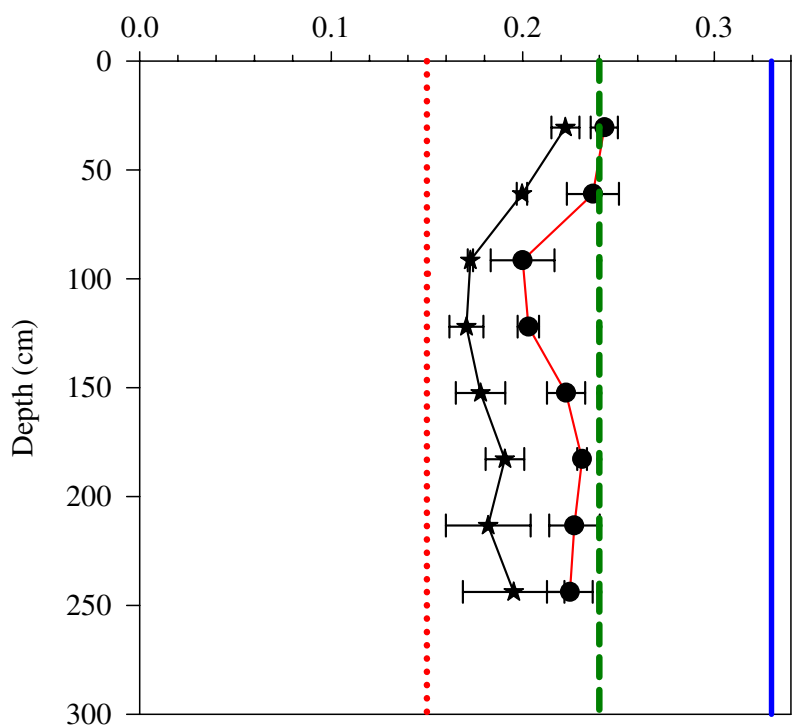

Fig. 9 End of season soil water under mobile drip irrigation (MDI) and LESA in two studies at two irrigation capacities (IC) of $6.2 \mathrm{and} 3.1 \mathrm{~mm} /$ day at the Kansas State University, SWREC near Garden City, Kansas

Fig. 10 Center pivot wheel tracks in under mobile drip irrigation and LESA at the Kansas State University SWREC, near Garden City
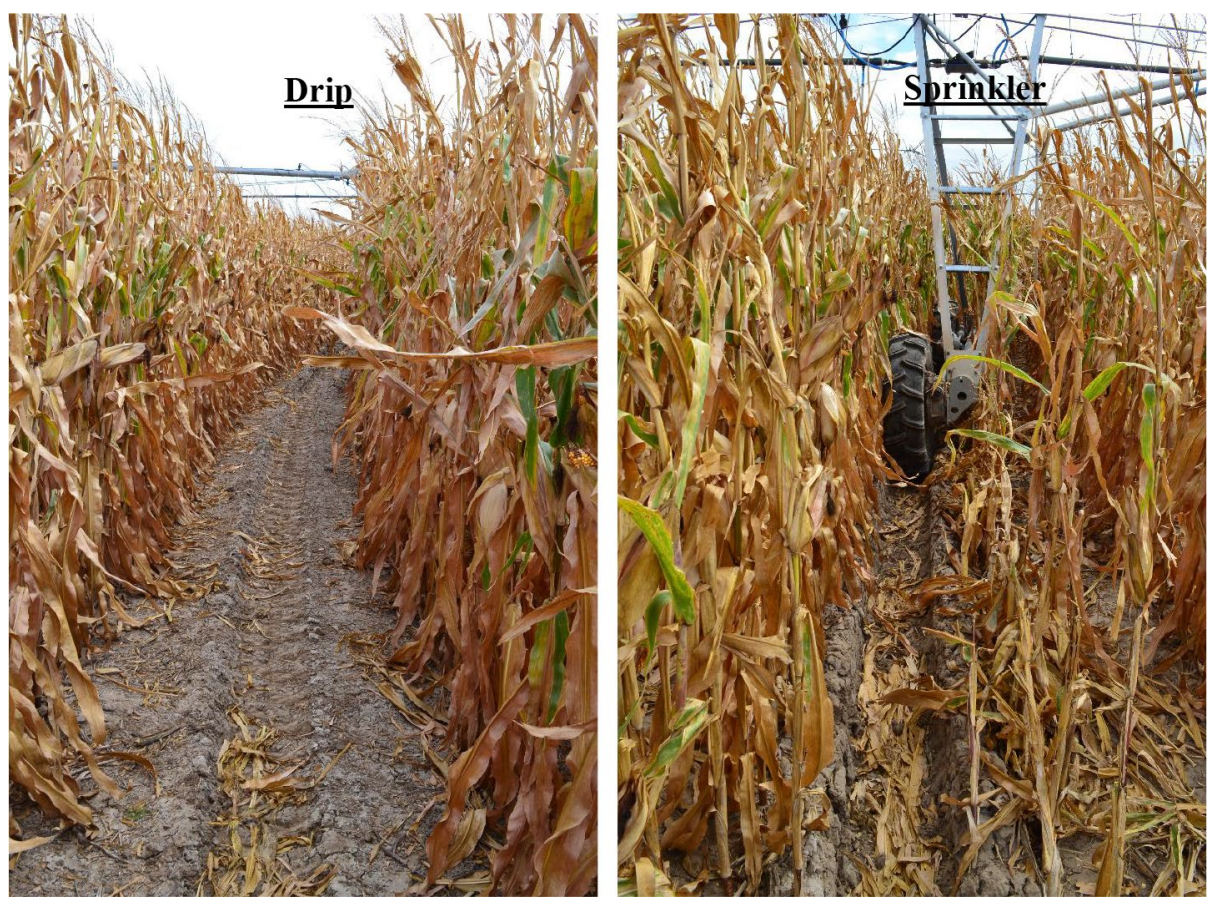

positive impact on corn yield. Corn yield is mainly influenced by ears per unit area, kernel number per ear and kernel weight. The lack of differences in these numbers (Table 2) explains the lack of differences in measured yield. Also, there was no significant difference in above ground biomass between MDI and spray nozzles within each study. However, harvest index measured in this study was higher than what was reported by Stewart and Peterson (2014) for various locations in the Southern High Plains probably due to differences in genotype by environment by management interactions.

\section{Crop water use}

Crop water use under Study 1 was 757 and $737 \mathrm{~mm}$ for MDI and LESA, respectively. Under high irrigation capacity, 


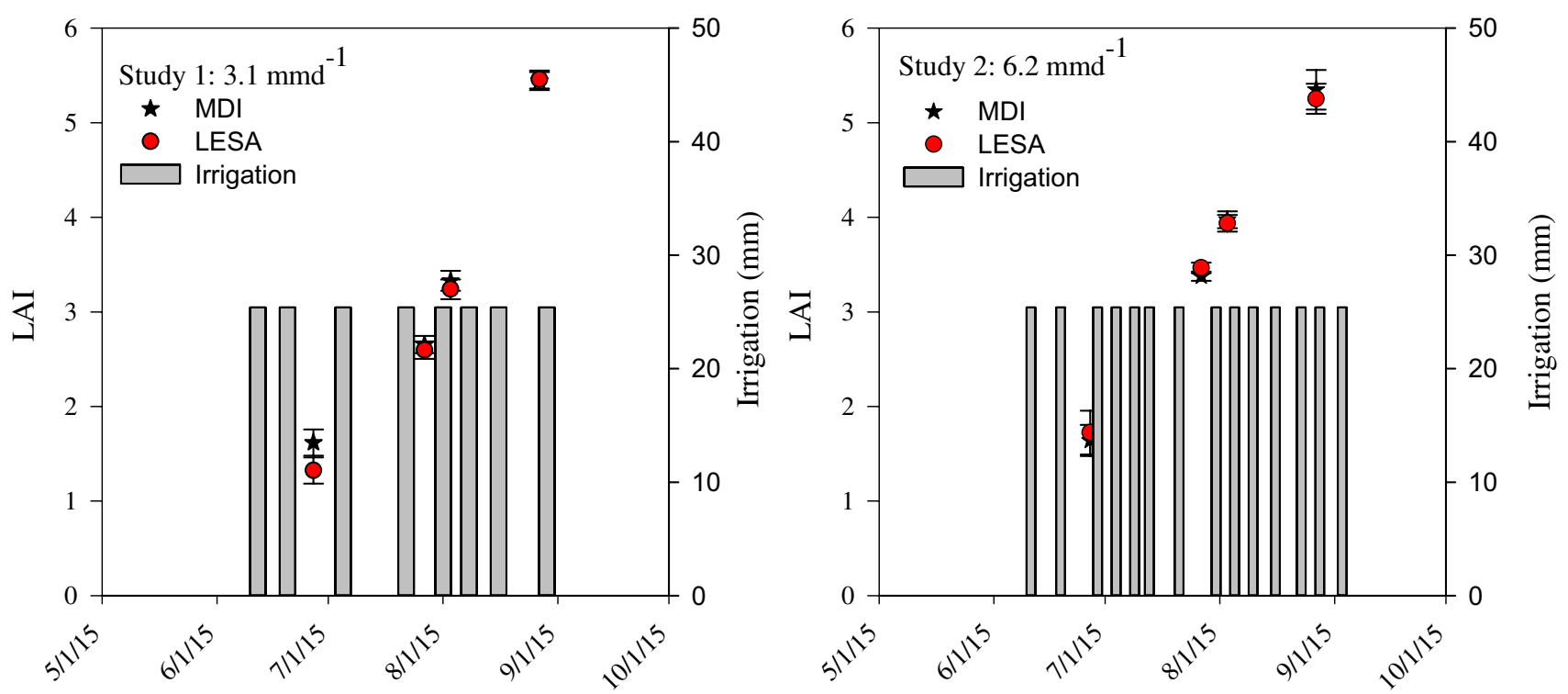

Fig. 11 Leaf area index (with standard error bars) from two studies under mobile drip irrigation and low elevation spray application during the 2015 growing season at the Kansas State University, SWREC near Garden City

Table 2 Yield and yield components $( \pm$ standard deviations) from two corn studies under mobile drip irrigation and LESA during the 2015 growing season (treatments not compared across studies) at the Kansas State University, SWREC near Garden City Kansas

\begin{tabular}{clllll}
\hline & Yield (Mg/ha) & Dry matter $(\mathrm{Mg} / \mathrm{ha})$ & Harvest index & $\begin{array}{l}\text { Kernel mass at } \\
15.5 \% \mathrm{MC}(\mathrm{mg})\end{array}$ & Kernels per ear \\
\hline Study 1 & & $6.5 \mathrm{~mm} /$ day & & & \\
MDI & $15.6 \pm 0.54 \mathrm{a}$ & $23.8 \pm 4.0 \mathrm{c}$ & 0.67 & $599 \pm 35 \mathrm{e}$ & $340 \pm 11 \mathrm{~g}$ \\
Spray & $16.0 \pm 0.86 \mathrm{a}$ & $25.1 \pm 2.0 \mathrm{c}$ & 0.62 & $631 \pm 47 \mathrm{e}$ & $332 \pm 16 \mathrm{~g}$ \\
Study 2 & & $3.2 \mathrm{~mm} /$ day & & & \\
MDI & $15.2 \pm 0.46 \mathrm{~b}$ & $26.2 \pm 4.7 \mathrm{~d}$ & 0.60 & $621 \pm 42 \mathrm{f}$ & $322 \pm 16 \mathrm{~h}$ \\
Spray & $13.8 \pm 1.41 \mathrm{~b}$ & $22.3 \pm 5.7 \mathrm{~d}$ & 0.63 & $579 \pm 85 \mathrm{f}$ & $311 \pm 24 \mathrm{~h}$ \\
\hline
\end{tabular}

Same letters indicate no significant differences within each study based on the GLIMMIX Proc in SAS studio (2016)

$M C$ moisture content, $M D I$ mobile drip irrigation
MDI used approximately $2 \%$ more water compared to LESA. Crop water use under Study 2 was 574 and $592 \mathrm{~mm}$ for MDI and LESA, respectively. Under low irrigation capacity, MDI used approximately $3 \%$ less water compared to LESA. The differences in seasonal crop water use (ETc) could be attributed to differences in irrigation application amounts between the two studies. Gross irrigation applications for Studies 1 and 2 were 356 and $203 \mathrm{~mm}$, respectively. High irrigation amounts under Study 1 probably increased water losses in the form of soil water evaporation. Deep drainage estimated using Stone et al. (1996) indicated that this component of the water balance was negligible (less than $1 \mathrm{~mm}$ on average). Corn crop water use measured in this study is within ranges of 505-790 $\mathrm{mm}$ reported by other investigators in western Kansas (Stone et al. 1996; Lamm et al. 2009; Schlegel et al. 2012; Klocke et al. 2015; Kisekka and Lamm 2016). Irrigation application method might not reduce total crop water use but could influence the partitioning between evaporation and transpiration.

The effect of application method on water productivity and irrigation water use efficiency was also not significant in both studies as shown in Table 3. In Study 1, average water productivity for MDI and LESA was 2.1 and $2.2 \mathrm{~kg} /$ $\mathrm{m}^{3}$, respectively. In Study 2, average water productivity for MDI and LESA was 2.7 and $2.3 \mathrm{~kg} / \mathrm{m}^{3}$, respectively. Similarly, irrigation water use efficiency was not significantly different in both studies (Table 3). However, it can be seen from Table 3 that water productivity and IWUE were higher under low irrigation capacity, implying that irrigation water was used more efficiently as the number of irrigation applications was reduced. Results from Table 3 also indicate that drainage losses from a $2.4 \mathrm{~m}$ soil profile were negligible. Water productivity reported in this study is slightly higher than those in earlier investigations by Schlegel et al. (2012) for 
Table 3 Crop water use, water productivity, irrigation water use efficiency and deep drainage from two corn studies under mobile drip irrigation and LESA during the 2015 corn growing season (treatments not compared across studies) at the Kansas State University, SWREC near Garden City Kansas

\begin{tabular}{cllll}
\hline & ETc $(\mathrm{mm})$ & WP $\left(\mathrm{kg} / \mathrm{m}^{3}\right)$ & IWUE $\left(\mathrm{kg} / \mathrm{m}^{3}\right)$ & $\begin{array}{l}\text { Deep drainage } \\
(\mathrm{mm})\end{array}$ \\
\hline Study 1 & $6.5 \mathrm{~mm} /$ day & & & \\
MDI & $759 \pm 26 \mathrm{a}$ & $2.1 \pm 0.2 \mathrm{c}$ & $4.4 \pm 0.3 \mathrm{e}$ & $0.8 \pm 0.2 \mathrm{~g}$ \\
Spray & $737 \pm 73 \mathrm{a}$ & $2.2 \pm 0.4 \mathrm{c}$ & $4.5 \pm 0.5 \mathrm{e}$ & $0.5 \pm 0.6 \mathrm{~g}$ \\
Study 2 & $3.2 \mathrm{~mm} /$ day & & & \\
MDI & $574 \pm 36 \mathrm{~b}$ & $2.7 \pm 0.3 \mathrm{~d}$ & $7.5 \pm 0.5 \mathrm{f}$ & $0.6 \pm 0.7 \mathrm{~h}$ \\
Spray & $592 \pm 36 \mathrm{~b}$ & $2.3 \pm 0.5 \mathrm{~d}$ & $6.8 \pm 1.4 \mathrm{f}$ & $0.1 \pm 0.1 \mathrm{~h}$ \\
\hline
\end{tabular}

Treatment means with the same letter are not significantly different at $5 \%$ level

ETc seasonal evapotranspiration, WP water productivity, IWUE irrigation water use efficiency, $M D I$ mobile drip irrigation

fully irrigated corn but similar to values reported by Kisekka and Lamm (2016) the differences could be due to differences in hybrids and irrigation management between the studies. There appears to be potential to improve water productivity by MDI, especially under limited irrigation capacity.

\section{Evaluation of new MDI design criteria}

Statistical uniformity $\left(U_{\mathrm{s}}\right)$ was estimated in the field in all four spans of the center pivot following the ASAE EP 405.1 (2014) standard. $U_{\mathrm{s}}$ was found to be good ranging between 85 to $90 \%$. The good $U_{\mathrm{s}}$ could be attributed to the pressure compensating characteristics of the drip line used in this study. The 130 micron disc filter with a flow rating of $45.4 \mathrm{~m} 3 / \mathrm{h}$ installed at the pump station was able to prevent any potential emitter clogging. Emitter clogging was a major problem in earlier PMDI designs as reported in Olson and Rogers (2007). Pressure gauges were installed at the inlet and outlet of the filter and flushing was done whenever the pressure differential between the two pressure gauges approached 0.5 bars. In addition, drip lines were routinely monitored for any possible clogging but clogging did not occur. The dual application design enabled switching between spray nozzles and MDI earlier in the season to enable incorporation of dry nitrogen fertilizer that was applied preplant. This type of flexibility would also be very useful for enabling germination in dry years, which can be a serious problem in SDI. Drag on the center pivot was not quantitatively measured in this study. However, we observed that during operation drip lines long than $33 \mathrm{~m}$ spaced at 1.52 exerted substantial force on the plastic drops. We recommend that for outer spans or high flow irrigation systems, high flow rate emitters or closer spacing of the laterals should be considered. Using rigid PVC drops, steel cables and planting in circles improved the ability of the drip to precisely be positioned on the ground. Occasionally the drip line was observed to move into the canopy. This problem could be mitigated using accurate GPS during circular planting and having a mechanism to easily offset the position of the drop and consequently the drip line. The flex hose shown in Fig. 2 enabled reversing the center pivot without kinking the drip line which was confirmed in this study. We did not observe any runoff in this study all the irrigation water applied stayed on the field. We also observed that MDI did not have deep wheel tracks associated with LESA and other sprinkler packages.

\section{Future work on MDI}

There are still many unanswered questions related to the performance of MDI. For example, how does MDI compare to in-canopy sprinklers or LEPA systems in terms of application efficiency and uniformity? There are questions related to water productivity, for example how does MDI affect the partitioning between evaporation (E) and transpiration $(\mathrm{T})$ ? We propose that future studies quantity $\mathrm{E}$ and $\mathrm{T}$ under the various irrigation application methods and how this portioning affects water productivity. Producers also wish to know what would be the optimum lateral spacing and length under MDI to eliminate runoff and ensure optimum soil water redistribution under different soil types. Future research could answer these questions through a combination of field experiments, and computer simulation of variably saturated flow. Other questions include at what well capacity should a producer change from spray to MDI? Could fertigation with MDI improve yields? There are also questions related to germination with MDI in dry years as well as the effect of MDI on herbicide and dry fertilizer incorporation. While the dual system that allows for quick switching between drip and sprinkler irrigation on new MDI systems might solve the problem, scientific data are needed to confirm performance of the dual system. There are also questions related to the cost of retrofitting a center pivot to MDI. We suggest that future research explores the economics of MDI under different well capacities and crops. There also operational questions such as the effect of dragging drip lines on their longevity, clogging and rodent damage. Such questions could be answered through long-term observation of MDI system performance.

\section{Conclusion}

Declining groundwater levels in the Ogallala aquifer due to withdrawals exceeding annual recharge has resulted in diminished well capacities that eventually become incapable of meeting full crop water needs. Precision irrigation 
technologies such as Mobile Drip Irrigation (MDI) are needed to help producers to maintain productivity with limited water by eliminating nonproductive evaporation losses. MDI involves attaching drip lines to center pivot drops. Two studies were conducted to compare soil water evaporation under MDI and LESA, assess soil water redistribution under MDI, compare end-of-season profile soil water under MDI and LESA at two irrigation capacities 3.1 and $6.2 \mathrm{~mm} /$ day and to investigate design objectives that were implemented to overcome problems of earlier MDI designs. Results indicate that soil water evaporation measured using mini-lysimeters was lower under MDI compared to LESA on average by $35 \%$. Soil water redistribution was adequate (equal vertical and lateral redistribution) under drip line spacing of $152 \mathrm{~cm}$ on Ulysses silt loam soils under the $6.2 \mathrm{~mm} /$ day irrigation capacity. There was significantly higher end of season soil water under MDI compared to sprinklers at the $3.1 \mathrm{~mm} /$ day irrigation capacity. Statistical uniformity of MDI was good ranging between 85 to $90 \%$. Even with circular planting, drip lines were observed to occasionally move into the corn canopy. Emitter clogging was virtually eliminated using a disc filter. Dual application mode (MDI and LESA) helped to incorporate fertilizers earlier in the season. No runoff was observed under MDI plots. In water-limited environments, MDI has the potential to improve irrigation efficiency and water productivity. There are still many unanswered questions related to MDI that need to be addressed before mechanized sprinkler-irrigated farmers can use their existing systems to harness the benefits of drip irrigation.

Acknowledgements This research was supported in part by Ogallala Aquifer Program, a consortium of the USDA Agricultural Research Service, Kansas State University, Texas AgriLife Research, Texas AgriLife Extension Service, Texas Tech University, and West Texas A\&M University and the Kansas Water Office, the Kansas State University Global Food Systems initiative and Foundation for Food and Agricultural Research. In kind support was also received from DragonLine Inc., Monsanto and Netafim. This is contribution number 17-169-J from the Kansas Agricultural Experiment Station. The authors thank the anonymous reviewers for their constructive comments.

Open Access This article is distributed under the terms of the Creative Commons Attribution 4.0 International License (http://creativecommons.org/licenses/by/4.0/), which permits unrestricted use, distribution, and reproduction in any medium, provided you give appropriate credit to the original author(s) and the source, provide a link to the Creative Commons license, and indicate if changes were made.

\section{References}

Amir I, Dag J (1993) Lateral and longitudinal wetting patterns of very low energy moving emitters. Irrig Sci 13:183-187

ASAE EP405.1 (2014) Design and installation of microirrigation systems, American Society of Agricultural Engineers (ASAE)
Bar-Yosef B, Sheikholslami MR (1976) Distribution of water and ions in soils irrigated and fertilized from a trickle source. Soil Sci Soc Am J 40:575-582

Colaizzi PD, Lamm FR, Howell TA, Evett SR (2006) Crop production comparison under various irrigation systems. In: Proc. Central Plains Irrigation Conference, Colby, KS., Feb. 21-22, 2006. Available from CPIA, 760 N. Thompson, Colby KS, pp 189-207

Derbala A (2003) Development and evaluation of mobile drip irrigation with center pivot irrigation machines. Ph. D., Thesis publ., Giessen University, Giessen

Evett SR, Colaizzi PD, Howell TA (2005) Drip and evaporation. In: Colby KS, Proc. central plains irrigation conference, Feb. 2005. Available from CPIA, 760 N. Thompson, Colby KS. pp 33-39

Hachum AY, Alfaro JF, Willardson LS (1976) Water movement in soil from a trickle source. ASCE J Irrig Drain Div 102(IR2):179-192

Helweg JO (1989) Evaluating traveling trickle center pivot. ICID Bull 38(1):13-20

Howell TA, Phene CJ (1983) Distribution of irrigation water from a low pressure, lateral-moving irrigation system. Trans ASAE 26(5):1422-1429

Howell TA, Schneider AD, Tolk JA (1991) Sprinkler evaporation losses and efficiency. In: Proc. central plains irrigation short course. Manhattan, Kans.: Kansas State University Cooperative Ext. Ser, pp 69-89

Keller J, Bliesner RD (2001) Sprinkle and trickle irrigation. The Blackburn Press

Kisekka I, Lamm FR (2016) Response of drought tolerant and conventional corn to limited irrigation. Kansas Agric Exp Stat Res Rep. doi:10.4148/2378-5977.1254

Klocke N, Currie R, Kisekka I, Stone L (2015) Corn and grain sorghum response to limited irrigation, drought, and hail. Appl Eng Agric 30(6):915-924

Lamm FR, Aiken RM, Abou Kheira AA (2009) Corn yield and water use characteristics as affected by tillage, plant density and irrigation. Trans ASABE 52(1):133-143

Lamm FR, Howell TA, Bodovsky JP (2012) Erraticity of Sprinkler Irrigated Corn Proceedings of the 24th Annual Central Plains Irrigation Conference, Colby, Kansas, February 21-22, 2012 Available from CPIA, 760 N. Thompson, Colby, Kansas

Levin I, Van Rooyen PC, Van Rooyen FC (1979) The effect of discharge rate and intermittent water applications by point source on the soil moisture distribution pattern. Soil Sci Soc Am J 43:8-16

McGuire V (2012) Water-level and storage changes in the high plains aquifer, predevelopment to 2011 and 2009-11, US Geological Survey Scientific Investigations Report, 2012-5291, p 15. http:// pubs.usgs.gov/sir/2012/5291/

Mostaghimi S, Mitchell JK, Lembke WD (1982) Effect of discharge rate on distribution of moisture in heavy soils irrigated from a trickle source. Trans ASAE 25(4):975-980

Olson B, Rogers D (2007) Comparing drag hoses verses sprinklers on corn irrigated by a center pivot. Appl Eng Agric 24(1):41-45

Rawlins SL, Hoffman GW, Merrill SD (1974) Traveling trickle system. In: Proc. of the second international drip irrig. congr., San Diego, pp 184-187

SAS Institute Inc. (2016) SAS ${ }^{\circledR}$ Studio 3.6. User's Guide, Cary: SAS Institute Inc., 2016

Schlegel AJ, Stone LR, Dumler TJ, Lamm FR (2012) Managing diminished irrigation capacity with preseason irrigation and plant density for crop production. Trans ASABE 55(2):525-531

Schneider AD (2000) Efficiency and uniformity of the LEPA and spray sprinkler methods: a review. Trans ASAE 43(4):937-944

Schneider AD, Howell TA (1993) Reducing sprinkler water losses. In: Proc. central plains irrigation shortcourse, February, 2-3, 1993, Sterling, pp 43-46 (methods: a review. Trans ASAE 43(4):937-944) 
Schwank LJ, Hanson BR (2006) Surface drip irrigation. In: Lamm RF, Ayars JE, Nakayama FS (eds) Microirrigation for crop production. Elservier, Netherlands, pp 431-471

Stewart BA, Peterson GA (2014) Managing green water in dryland agriculture. Agron J 106:1-10. doi:10.2134/agronj14.0038

Stone LR, Schlegel AJ, Gwin RE, Khan AH (1996) Response of corn, grain sorghum, and sunflower to irrigation in the high plains of kansas. Agric Water Manag 30(251):259
Stone LR, Klocke NL, Schlegel AJ, Lamm FR, Tomsicek DJ (2011) Equations for drainage component of the field water balance. App Eng Agric 27:345-350

UNESCO (2013) Water cooperation 2013. http://www.unwater.org/ water-cooperation-2013/water-cooperation/en/. Accessed 14 Jan 2015 